Gut, 1983, 24, 818-824

\title{
Small intestinal absorption of amino acids and a dipeptide in pancreatic insufficiency
}

\author{
P J MILlA, A KILBY, U B RASSAM, R ERSSER, AND J T HARRIES* \\ From the Hospital for Sick Children, Great Ormond Street, London, and The Institute of Child Health, \\ Guilford Street, London
}

SUMmARY In this study a perfusion technique has been used to investigate in vivo jejunal absorption and transmural potential difference evoked by the neutral amino acids phenylalanine ( 56 or $20 \mathrm{mmol} / \mathrm{l})$ and glycine $(20 \mathrm{mmol} / \mathrm{l})$, the dibasic amino acid lysine $(56 \mathrm{or} 5 \mathrm{mmol} / \mathrm{l})$, and a dipeptide glycyl-1-phenylalanine $(20 \mathrm{mmol} / \mathrm{l})$ in 11 children with pancreatic insufficiency due to cystic fibrosis and in three children with other causes of exocrine pancreatic insufficiency. Net absorption and potential difference evoked by phenylalanine in both cystic fibrosis and pancreatic insufficiency, and net absorption of glycine in cystic fibrosis were significantly reduced; but the absorption of lysine and glycyl-1-phenylalanine was normal. Absorption of the constituent amino acids from the dipeptide was normal or increased in cystic fibrosis. Thus, these studies show a defect in active absorption of neutral amino acids in cystic fibrosis with pancreatic insufficiency and exocrine pancreatic insufficiency. We speculate that pancreatic factors participate in neutral amino acid absorption.

It is well established that, despite adequate pancreatic replacement therapy, patients with pancreatic insufficiency due to cystic fibrosis excrete increased amounts of faecal nitrogen and fat. ${ }^{12}$ The increased faecal nitrogen is accounted for by both unhydrolysed proteins and amino acids of dietary origin. ${ }^{3}$ The faecal amino acids are derived in part from intraluminal bacterial degradation of intact proteins. ${ }^{3}$ Recent studies have shown defective in vitro uptake of neutral amino acids by jejunal biopsy material obtained from patients with cystic fibrosis, ${ }^{4}$ and impaired in vivo absorption of a synthetic neutral amino acid, ${ }^{5}$ suggesting that small intestinal malabsorption of certain amino acids may also contribute to the increased faecal nitrogen losses in cystic fibrosis.

We have utilised a steady-state perfusion technique to investigate the in vivo absorption of the neutral amino acids phenylalanine and glycine, the dibasic amino acid lysine, and a dipeptide glycyl-1-phenylalanine in children with cystic fibrosis, in those with other causes of exocrine

\footnotetext{
Address for correspondence: Dr P J Milla, Department of Child Health. Institute of Child Health, 30 Guilford Street, London WC1.

* Since this paper was written Professor J T Harries has unfortunately died. Received for publication 8 November 1982
}

pancreatic insufficiency, and in control subjects. The results have in part been reported in abstract form. ${ }^{6}$

\section{Methods}

SUBJECTS

Eleven patients with pancreatic insufficiency due to cystic fibrosis with a mean age of 4.1 years (range $1 \cdot 0-10 \cdot 2$ years), three patients with other forms of exocrine pancreatic insufficiency, two with Shwachman's syndrome aged 2.2 and 4.3 years, one with acquired pancreatic insufficiency after chicken pox, and 16 control subjects with a mean age of 4.0 years (range $0.9-10.0$ years) were investigated. The diagnosis of cystic fibrosis was based on raised sweat sodium concentrations $(>70 \mathrm{mmol} / \mathrm{l})$, typical clinical symptoms and signs, and pancreatic insufficiency. Shwachman's syndrome was diagnosed on the basis of a combination of pancreatic insufficiency, impaired growth unrelated to dietary intake and/or malabsorption, intermittent neutropenia, defective neutrophil mobility, and skeletal anomalies. ${ }^{7}$ Pancreatic function was assessed by determining the activity of trypsin, amylase, and lipase in duodenal juice in response to a test meal as previously described. ${ }^{8}$ In all patients 
with pancreatic insufficiency there was a marked reduction in pancreatic enzyme activity compared with our established normal range. ${ }^{8}$ The control subjects comprised children with the irritable bowel syndrome who had a normal jejunal mucosa on light microscopy and no demonstrable evidence of malabsorption.

Growth was normal at the time of the study in both the cystic fibrosis and control subjects. Cystic fibrosis height velocity three months before and after study varied between the 50 and 90 centiles and height between 10-75 centiles; weight velocity between the 25 and 90 centiles, and weight between 10-50 centiles. Urinary hydroxy proline/creatinine ratio was 49-102 (normal range 30-254). At the time of study the control subjects' height velocity varied between 25 and 75 centiles and height between 25-75 centiles; weight velocity between 10 and 75 centiles, weight 10-50 centiles, and urinary hydroxy proline ratio $45-89$.

Neither the patients nor the control subjects received any drugs or pancreatic supplements for 72 hours before perfusion. The studies were approved by the Standing Committee on Ethical Practice of the Hospital for Sick Children, and informed written consent was obtained from parents.

The proximal $20 \mathrm{~cm}$ of the jejunum was perfused using a double-lumen tube at a rate of $8 \mathrm{ml} / \mathrm{min}$ as previously described. ${ }^{10}$ After a 30 minute equilibration period, effluent was collected on ice in 10 minute aliquots for a further 30 minutes. All the solutions perfused contained an amino acid or dipeptide, polyethylene glycol 4000 (3 g/l) (PEG, a water soluble non-absorbable volume marker), ${ }^{11}$ $\mathrm{KCl}(4 \mathrm{mmol} / \mathrm{l}), \mathrm{NaHCO}_{3}(25 \mathrm{mmol} / \mathrm{l})$ their osmolalities were adjusted to $285-290 \mathrm{mosm} / \mathrm{kg}$ by the addition of $\mathrm{NaCl}$; $\mathrm{pH}$ was adjusted to 7.0 by gassing with $\mathrm{CO}_{2}$. After the 30 minute equilibration period PEG concentration in the three 10 minute aliquots of effluent was steady indicating that a steady state had been achieved. Amino acid and dipeptide concentrations were determined in each of the 10 minute collections as appropriate. The $\mathrm{pH}$ of the effluent did not differ significantly from the $\mathrm{pH}$ of the solutions perfused, and only trace amounts of peptidase activity could be detected in the effluent. ${ }^{12}$

Transmural potential difference was monitored by a 23 gauge syringe needle placed in the inlet limb of the perfusion tube which served as a flowing intraluminal electrode. The reference electrode consisted of isotonic bicarbonate saline in a 23 gauge butterfly needle which was inserted under the skin of the leg. The intraluminal electrode and reference electrode were connected via isotonic bicarbonate saline bridges and disposable $5 \mathrm{ml}$ syringes containing $\mathrm{Ag} / \mathrm{AgCl}$ half cells to the input terminals of a battery powered voltmeter (Levell TM9B), the output was displayed on a chart recorder (Vitatron 2001). The asymmetry between the intraluminal and subcutaneous electrodes was measured before and at the end of the perfusion by placing the distal ends of the saline bridges in a solution of isotonic bicarbonate saline. The asymmetry potential was always less than $1 \mathrm{mV}$. Potential difference measurements are presented as the mean recorded during the steady state period, the mucosa being negative relative to the serosa. The 'resting' potential difference was recorded by perfusing normal saline before the first equilibration period.

Initially control and cystic fibrosis subjects were perfused with equimolar concentrations $(56 \mathrm{mmol} / \mathrm{l})$ of phenylalanine and lysine in random order. It was possible, however, that this concentration of the amino acids might saturate their transport systems and mask any more specific effects on their 'carriers' that might have been observed at concentrations approximating the apparent $\mathrm{K}_{\mathrm{m}}$ of the amino acids concerned. No information could be found regarding the kinetics of phenylalanine absorption in vivo in man and thus a group of control subjects $(n=4)$ were perfused with solutions containing 10 , 20,40 , and $60 \mathrm{mmol} / \mathrm{l}$ of phenylalanine in ascending order of concentration. A 30 minute equilibration period was allowed between each concentration perfused and effluent collected for a further 30 minutes in 10 minute aliquots. The data revealed an apparent $\mathrm{K}_{\mathrm{m}}$ and $\mathrm{V}_{\max }$ of $24.4 \mathrm{mmol} / \mathrm{l}$ and 12.8 $\mu \mathrm{mol} / \mathrm{cm} / \mathrm{min}$ respectively. Data regarding the kinetics of lysine absorption in man in the literature were widely discrepant, however, $\operatorname{Rey}^{13}$ using a system similar to our own in young children found an apparent $K_{m}$ of approximately $80 \mathrm{mmol} / \mathrm{l}$, whereas a study in adults ${ }^{14}$ using different perfusion dynamics revealed an apparent $\mathrm{K}_{\mathrm{m}}$ of approximately $5 \mathrm{mmol} / \mathrm{l}$. Subjects were then perfused with lower concentrations of phenylalanine and lysine, 20 and 5 $\mathrm{mmol} / \mathrm{l}$ respectively, which for phenylalanine was close to the apparent $K_{m}$ in this system. As the concentration of lysine perfused in the first series of perfusions approximated the apparent $K_{m}$ found by Rey ${ }^{13}$ in this second series of perfusions, a lower concentration $(5 \mathrm{mmol} / \mathrm{l})$ close to the apparent $\mathrm{K}_{\mathrm{m}}$ found by Hellier et al $^{14}$ was perfused. Plasma amino acid concentrations were determined in peripheral venous blood collected by venepuncture immediately before the perfusion, and at the end of the phenylalanine and lysine perfusion periods.

In the final part of the study each subject was perfused with solutions containing either phenylalanine, glycine, or glycyl-1-phenylalanine at 20 $\mathrm{mmol} / \mathrm{l}$, and as in all other subjects the order of perfusion of test solutions was randomised. 
REAGENTS AND ANALYSIS

All reagents were of analytical grade and obtained from BDH Ltd, or Koch-Light Ltd. The amino acids and dipeptide were all found to be chromatographically homogenous.

Polyethylene glycol was assayed turbidometrically. ${ }^{15}$ Amino acids and dipeptide concentrations were estimated by ion exchange chromatography. ${ }^{16}$

\section{CALCULATIONS}

Rates of absorption were calculated according to standard formulae. ${ }^{17} 18$ The disappearance rates of dipeptide and the absorption rates of the constituent amino acids were calculated by the following formulae: ${ }^{18}$

$$
\begin{gathered}
D d=\frac{\left(D p-D e \times \frac{P e g}{P e g}\right) \times F}{S} \\
A a=\frac{n D p-\left[(n D e+C a) \times \frac{P e g p}{P e g e}\right] \times F}{S}
\end{gathered}
$$

where Dd $=$ dipeptide disappearance rate in $\mu \mathrm{mol} /$ $\mathrm{min} / \mathrm{cm} ; \mathrm{Dp}=$ concentration of dipeptide perfused; $\mathrm{De}=$ concentration of dipeptide in effluent; Peg $\mathrm{p}=$ concentration of polyethylene glycol perfused; Peg $\mathrm{e}=$ concentration of polyethylene glycol in effluent; $\mathrm{F}=$ rate of perfusion $\mathrm{ml} / \mathrm{min} ; \mathrm{S}=$ segment length in $\mathrm{cm} ; \mathrm{Aa}=$ amino acid absorption rate in $\mu \mathrm{mol} / \mathrm{min} / \mathrm{cm} ; \mathrm{n}=$ number of the same amino acid residues in dipeptide; $\mathrm{Ca}=$ concentration of constituent amino acid in free form in effluent in $\mu \mathrm{mol} / \mathrm{ml}$.

Absorption and disappearance rates are assumed to be synonymous for free amino acids, whereas disappearance rates of dipeptide may include absorption of intact dipeptide as well as hydrolysis to constituent amino acids. For each subject, rate of absorption is expressed as the mean of the three 10 minute periods. The results for each group are expressed as the mean \pm SEM and were analysed statistically by means of paired and unpaired Student's $t$ test.

\section{Results}

The results of the initial part of the study are shown in Fig. 1. There was a marked reduction in phenylalanine absorption in cystic fibrosis patients at both $56 \mathrm{mmol} / \mathrm{l}(\mathrm{p}<0.002)$ and $20 \mathrm{mmol} / \mathrm{l}(\mathrm{p}<0.005)$ compared with the control values; phenylalanine $(20$

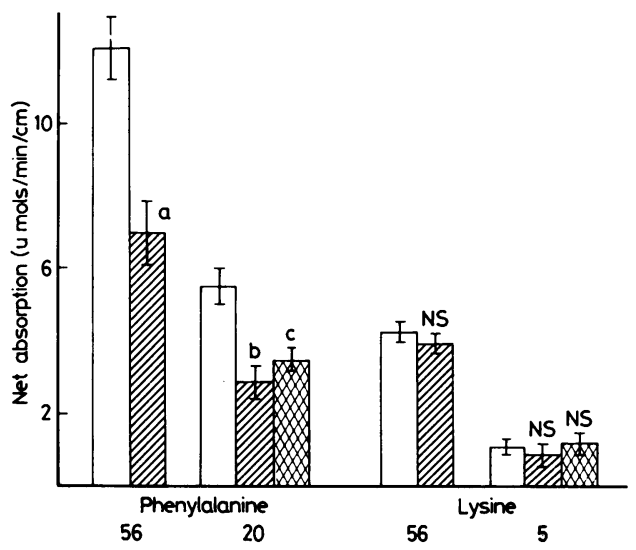

Fig. 1 Net jejunal absorption of phenylalanine and lysine: $\square=$ controls (6); $\mathbb{Z}=C F(6) ;$ 㥵 $=E P I(3)$. Figures in parentheses $=$ number of subjects. Histograms plotted as means \pm SEM. $a=$ control vs $\mathrm{CF}, \mathrm{p}<0.02 ; \mathrm{b}=$ control $v s$ $\mathrm{CF}, \mathrm{p}<0.005 ; \mathrm{c}=$ control vs EPI, $\mathrm{p}<0.05$.

$\mathrm{mmol} / \mathrm{l})$ absorption was also depressed $(\mathrm{p}<0.05)$ in the patients with exocrine pancreatic insufficiency; in contrast, lysine absorption was not statistically different from control values.

The mean 'resting' potential difference was similar in the control cystic fibrosis and exocrinepancreatic insufficiency groups $(3 \cdot 0 \pm 0 \cdot 10$, $2 \cdot 8 \pm 0 \cdot 15,2 \cdot 5 \pm 0 \cdot 20 \mathrm{mV}$ ) respectively. The potential difference evoked by phenylalanine $(56 \mathrm{mmol} / \mathrm{l})$ was reduced in the cystic fibrosis patients (control $7.95 \pm 0.65$; cystic fibrosis $4.06 \pm 0.62, p<0.002$ ), as was the case at the lower concentration for both the cystic fibrosis (control 5.40 $\pm 0 \cdot 20$; cystic fibrosis $3.9 \pm 0.21, \mathrm{p}<0.005)$, and exocrine pancreatic insufficiency patients (control $5 \cdot 40 \pm 0 \cdot 20$; exocrine pancreatic insufficiency $4 \cdot 1 \pm 0 \cdot 05, \mathrm{p}<0 \cdot 05)$. As reflected by the low potential difference values recorded, there was a significant reduction in water and $\mathrm{Na}^{+}$absorption at the higher concentration of phenylalanine perfused and secretion of water and $\mathrm{Na}^{+}$at the lower concentration of phenylalanine in the patients with cystic fibrosis and exocrinepancreatic insufficiency as seen in Table 1 . There was no difference in lysine evoked potential difference between the three groups at either concentration $(56 \mathrm{mmol} / 1$, control $8 \cdot 90 \pm 0 \cdot 50$; cystic fibrosis $8 \cdot 58 \pm 1 \cdot 08 ; 5 \mathrm{mmol} / 1$, control $5 \cdot 2 \pm 0 \cdot 19$; cystic fibrosis $5 \cdot 1 \pm 0 \cdot 16$; exocrine pancreatic insufficiency $5 \cdot 13 \pm 0 \cdot 12 \mathrm{mV}$ ). Lysine consistently provoked water and $\mathrm{Na}^{+}$secretion to a similar degree, however, in both patients and control subjects (Table 1). 


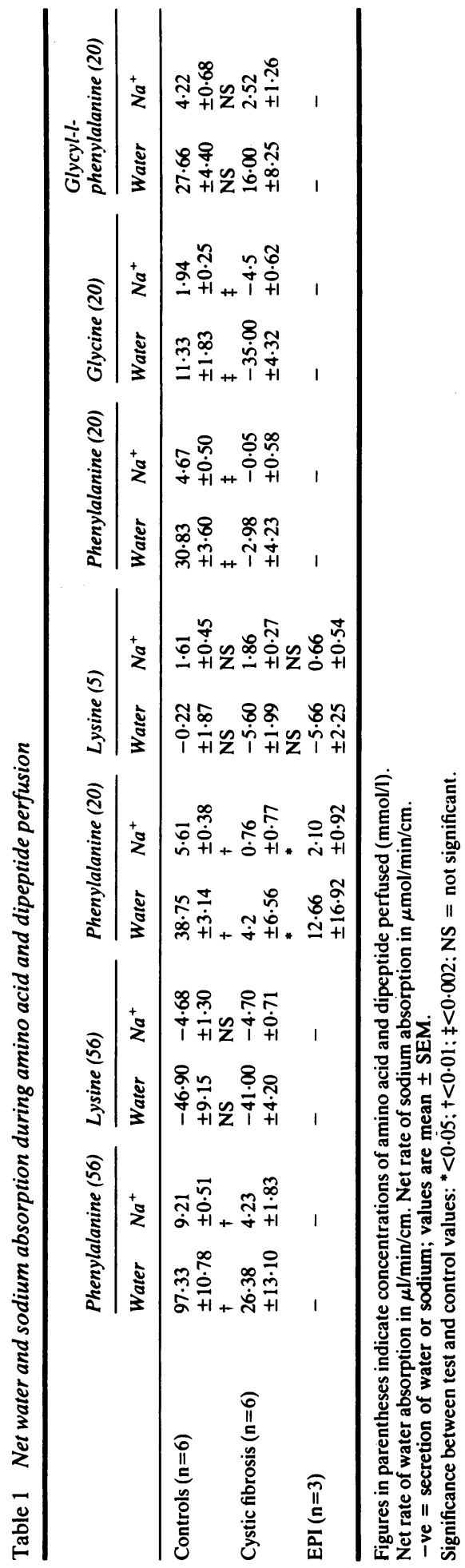


Table 2 Rise in plasma amino acid concentration after perfusion with phenylalanine $(20 \mathrm{mmol} / \mathrm{l})$ and lysine (5 mmol/l)

\begin{tabular}{|c|c|c|c|}
\hline & \multicolumn{3}{|c|}{ Plasma amino acid concentration ( $\mu \mathrm{mol} / \mathrm{l})$} \\
\hline & \multicolumn{2}{|l|}{ Phenylalanine } & \multirow[b]{2}{*}{ Lysine } \\
\hline & $\begin{array}{l}\text { Phenyl- } \\
\text { alanine }\end{array}$ & Tyrosine & \\
\hline Controls $(n=6)$ & $\begin{array}{l}570 \cdot 65 \pm 30 \cdot 42 \\
\ddagger\end{array}$ & $\begin{array}{l}67 \cdot 60 \pm 11 \cdot 49 \\
+\end{array}$ & $\begin{array}{l}162 \cdot 00 \pm 11 \cdot 18 \\
\text { NS }\end{array}$ \\
\hline$C F(n=6)$ & $\begin{array}{l}384 \cdot 50 \pm 27 \cdot 11 \\
\ddagger\end{array}$ & $\begin{array}{l}34 \cdot 00 \pm 8 \cdot 29 \\
*\end{array}$ & $\begin{array}{l}147 \cdot 80 \pm 14 \cdot 70 \\
\text { NS }\end{array}$ \\
\hline $\operatorname{EPI}(n=3)$ & $339 \cdot 70 \pm 29 \cdot 30$ & $55 \cdot 00 \pm 7 \cdot 70$ & $112 \cdot 00 \pm 16 \cdot 40$ \\
\hline
\end{tabular}

Data expressed as mean \pm SEM.

Significance between test and control values:

$*<0 \cdot 05:+\mathrm{p}<0 \cdot 02 ; \ddagger \mathrm{p}<0 \cdot 001$.

Table 2 shows the increments in the concentration of plasma phenylalanine, and tyrosine after perfusion with phenylalanine, $20 \mathrm{mmol} / \mathrm{l}$, and plasma lysine after perfusion with lysine, $5 \mathrm{mmol} / \mathrm{l}$. As the rise in plasma phenylalanine during phenylalanine perfusion will be modified by significant metabolism of absorbed phenylalanine to tyrosine during its first pass through the liver, plasma tyrosine was also measured to give an indication of this. The rise in plasma phenylalanine and tyrosine concentrations was reduced in the cystic fibrosis and

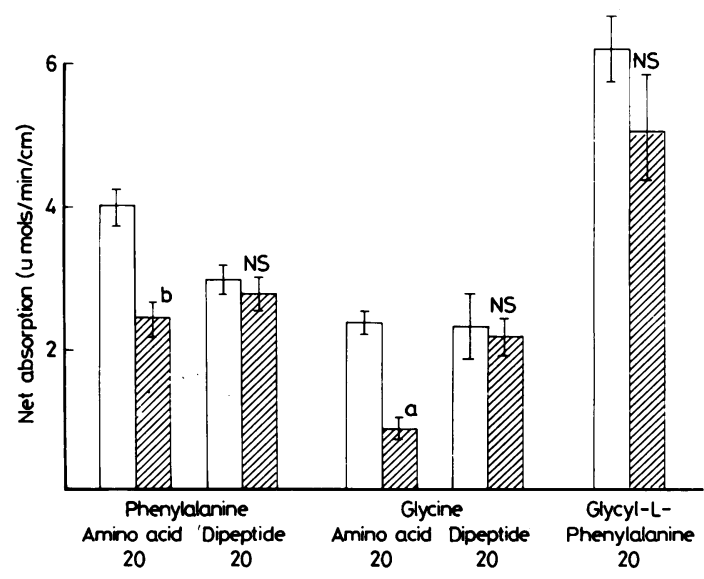

Fig. 2 Net jejunal absorption of phenylalanine and glycine compared with luminal disappearance of glycyl-lphenylalanine and absorption of its constituents: $\square=$ controls $(6) ; \forall=C F(5)$. Figures in parentheses $=$ number of subjects. Histograms plotted as means $\pm S E M . a=$ control vs $\mathrm{CF}, \mathrm{p}<0 \cdot 01 ; \mathrm{b}=$ control $v s$ $\mathrm{CF}, \mathrm{p}<0 \cdot 02$. exocrine pancreatic insufficiency $(p<0.001$ and $\mathrm{p}<0.005$ respectively) patients compared with controls, but there was no difference in lysine increments between the groups. The results of the final part of the study when phenylalanine, glycine, and glycyl-1-phenylalanine were perfused at concentrations of $20 \mathrm{mmol} / \mathrm{l}$ are shown in Fig. 2. Absorption of free phenylalanine was again found to be depressed in cystic fibrosis patients $(\mathrm{p}<0.02)$ as was absorption of the other neutral free amino acid glycine $(p<0 \cdot 01)$. The mean disappearance rate of glycyl-l-phenylalanine in cystic fibrosis patients was not significantly different from controls. During perfusion with phenylalanine and glycine, water and $\mathrm{Na}^{+}$absorption was reversed to secretion in the patients with cystic fibrosis whereas during glycyl-1-phenylalanine perfusion, there was no significant difference in water and $\mathrm{Na}^{+}$absorption between the cystic fibrosis patients and the control subjects (Table 1). The fact that absorption rates of phenylalanine and glycine from the dipeptide were normal or increased (glycine $\mathrm{p}<0.02$ ) in cystic fibrosis supports the notion that intact dipeptide absorption was normal in the cystic fibrosis group.

\section{Discussion}

This study confirms and extends previous studies of impaired amino acid absorption in cystic fibrosis ${ }^{4} 5$ and represents the first in vivo perfusion study of amino acid absorption in cystic fibrosis. We have defined, for the first time to our knowledge, the kinetics of phenylalanine absorption in the jejunum of normal children in vivo and have shown that in cystic fibrosis there is reduced absorption of phenylalanine at concentrations which both saturate the transport system and are close to the apparent $\mathrm{K}_{\mathrm{m}}$ of the study system used. These findings might suggest that in cystic fibrosis there are both reduced numbers of transport sites, and that they do not function as well as in control subjects. It would be necessary, however, to investigate phenylalanine absorption over a wider range of concentrations than has been studied here to confirm this suggestion. We have clearly shown impaired absorption of two structurally dissimilar neutral amino acids in cystic fibrosis, one polar-glycine, the other non-polar-phenylalanine; both are absorbed by the same group specific transport system. Previous studies have shown defective absorption of neutral amino acids leucine and cyclo-leucine in vitro $^{4}$ and 3-methoxy-phenylalanine in vivo. ${ }^{5}$ It seems likely therefore that the neutral amino acid transport system is operating in a defective manner in patients with pancreatic insufficiency owing to cystic fibrosis. Neutral amino acid stimulated water 
and electrolyte absorption and its reversal to secretion together with the reduced transmural potential difference seen in the patients with cystic fibrosis and exocrine pancreatic insufficiency, can almost entirely be accounted for by the reduction in neutral amino acid absorption. The dibasic amino acid lysine, however, which is absorbed by a transport system quite distinct to that utilised by neutral amino acids $^{19}$ appears to be absorbed normally under the same conditions but to be quite certain a full kinetic study should have been carried out.

Perfusion with the dipeptide glycyl-1-phenylalanine showed that yet another transport system, which differs from both the dibasic and the neutral amino acid system, ${ }^{20}$ also appeared to be unaffected. The increased absorption of glycine from the dipeptide solution compared with the glycine solution in cystic fibrosis, and the abolition of the difference in absorption rates of both phenylalanine and glycine between cystic fibrosis and control subjects seen when the dipeptide was perfused provides further evidence that dipeptides are transported by separate systems from amino acids.

The nutritional significance of the defect in neutral amino acid transport is not clear. The products of luminal protein digestion are predominantly small peptides, in view of the normal dipeptide absorption it would seem unlikely that there would be much malabsorption of the products of digestion. It is known, however, that faecal nigtrogen excretion is significantly increased in cystic fibrosis ${ }^{12}$ and that this is at least in part because of increased excretion of faecal amino acids. $^{3}$

The data cannot be explained in simple physical terms such as an alteration in the thickness of the unstirred water layer in pancreatic insufficiency states, as the defect in absorption seems to be restricted to neutral amino acids absorption of a dibasic amino acid, and a dipeptide being unaffected.

There are a number of possible explanations for the impaired neutral amino acid absorption in cystic fibrosis, including malnutrition, reduced pancreatic secretion or a defect specific to the disease itself. Malnutrition would appear to be an unlikely cause in our patients as growth was similar to control subjects. By altering the state of dissociation of the amino acids (and therefore their polarity), impaired pancreatic secretions of bicarbonate might theoretically be implicated as an explanation; for example, reduction of luminal $\mathrm{pH}$ decreases lysine absorption in the experimental animal. ${ }^{21}$ This is unlikely, however, to be the case, as in our patients the perfusates were buffered with bicarbonate and the $\mathrm{pH}$ of the solutions did not alter during perfusion. A previous in vitro study had suggested that jejunal malabsorption of neutral amino acids might be because of a defect intrinsic to cystic fibrosis. ${ }^{4}$ In our study the defect in phenylalanine absorption was also present in patients with other forms of pancreatic insufficiency suggesting perhaps that pancreatic insufficiency per se was involved. There is evidence that pancreatic proteolytic enzymes $^{22}{ }^{23}$ and mucosal lysosomal hydrolases ${ }^{24}$ play a role in the turnover of brush border proteins, and thus may modulate brush border function. It is tempting to speculate that the present data could be explained on the basis of a reduction in the number of brush border transport sites, which also functioned less efficiently.

The authors thank Drs Dinwiddie, Mathew, and Norman for permission to study their patients. PJM gratefully acknowledges financial support given by the National Fund for Research into Crippling Diseases. We also thank the Cystic Fibrosis Trust for financial support.

\section{References}

1 Lapey A, Kattwinkel J, di Sant'Agnese PA, Laster L. Steatorrhoea and azotorrhoea and their relation to growth and nutrition in adolescents and young adults with cystic fibrosis. J Pediatr 1974; 84: 328-34.

2 Shmerling DH, Farrer JCW, Prader A. Fecal fat and nitrogen in healthy children and in children with malabsorption or maldigestion. Pediatrics 1970; 46: 690-5.

3 Seakins JWT, Ersser RS, Sibbons ISE. Studies on the origin of faecal amino acids in cystic fibrosis. Gut 1970; 11: $600-9$

4 Morin CL, Roy CC, Lasalle R, Bonin A. Small bowel mucosal dysfunction in patients with cystic fibrosis. $J$ Pediatr 1976; 88: 213-6.

5 Seakins JWT, Ersser R. Use of a semi-synthetic amino acid 3 methoxy phenyl-l-alanine to measure amino acid absorption. In: Bickel H, Stern J, eds. Inborn errors of calcium and bone metabolism. Lancaster: MTP Press, 1976: 304-36.

6 Milla PJ, Rassam UB, Ersser R, Harries JT. Defective small intestinal absorption of neutral non-polar amino acids in pancreatic insufficiency. (Abstract.) Gut 1978; 19: A440.

7 Aggett PJ, Cavanagh NPC, Matthew DJ, Pincott JR, Sutcliffe J, Harries JT. Shwachman's syndrome: a review of 21 cases. Arch Dis Child 1980; 55: 331-47. 
8 McCollum JPK, Muller DPR, Harries JT. A test meal for assessing intraluminal phase of absorption in childhood. Arch Dis Child 1977; 52: 887-9

9 Wharton BA, Sough S, Williams A, Kitts S, Pennock C. Urinary hydroxy proline: creatinine ratio. Range of normal and clinical application in British children. Arch "Dis Child 1972; 47: 74-9.

10 Milla PJ, Aggett PJ, Wolff OH, Harries JT. Studies in primary hypomagnesaemia: evidence for defective carrier mediated small intestinal absorption of magnesium. Gut 1979; 20: 1028-33.

11 Jacobson ED, Bondy DC, Broitman SA, Fordtran JC. Validity of polyethylene glycol in estimating intestinal water volume. Gastroenterology 1963; 44: 761-7.

12 Silk DBA, Kumar PJ, Perrett D, Clark ML, Dawson A. Amino acid and peptide absorption in patients with coeliac disease and dermatitis herpetiforms. Gut 1974; 15: $1-8$.

13 Rey F, Drillet F, Schmitz J, Rey J. Influence of flow rate on the kinetics of the intestinal absorption of glucose and lysine in children. Gastroenterology 1974; 66: $79-85$.

14 Hellier MD, Holdsworth CD, Perrett D. Dibasic amino-acid absorption in man. Gastroenterology 1973; 65: $613-8$

15 Hyden S. A turbidometric method for the determination of higher polyethylene glycols in biological materials. Kan Lanthr Hodsk Annlr 1956; 22: 139-45.
16 Ersser R. In: Gray C, Lim M, Stolle M, eds. High performance liquid chromatography in clinical chemistry. New York: Academic Press, 1976: 25-38.

17 Sladen GE, Dawson AM. Interrelationships between the absorption of glucose, sodium and water by the normal human jejunum. Clin Sci 1969; 36: 119-32.

18 Adibi AS, Morse EL. Intestinal transport of dipeptides in man: relative importance of hydrolysis and intact absorption. J Clin Invest 1971; 50: 2266-75.

19 Wiseman L. Absorption of amino acids. In: Code CF, ed. Handbook of Physiology, sect 6, vol 3 . Washington: American Physiological Society, 1968: 1277-308.

20 Matthews DM. Intestinal absorption of peptides. Physiol Rev 1975; 55: 537-608.

21 Segal S, Lowerstein M, Wallace A. Comparison of the transport characteristics of L-lysine by small intestine and kidney cortex. Gastroenterology 1968; 55: 386-91.

22 Kwong WK, Seetharam B, Alpers DH. Effect of exocrine pancreatic insufficiency on small intestine in the mouse. Gastroenterology 1978; 74: 1277-82.

23 Batt RM, Bush BM, Peters TJ. Biochemical changes in the jejunal mucosa of dogs with naturally occurring exocrine pancreatic insufficiency. Gut 1979; 20: 709-15.

24 Seetharam B, Grumme N, Goodwin C, Alpers DH. Differential sensitivity of intestinal brush border enzymes to pancreatic and lysosomal proteases. Life Sci 1976; 18: 89-95. 